\section{Effect of compressive loads on the tensile strength of concrete at high strain rates}

\author{
C. Tiniç*, E. Brühwilert
}

\section{SYNOPSIS}

This paper describes the behaviour of concrete subjected to tensile loads at high strain rates with and without compressive load histories. The tests, carried out at the laboratory of building materials of the Swiss Federal Institute of Technology, Zurich, show a considerable deterioration of the tensile strength due to initially applied compressive loads

\section{KEYWORDS}

Tension tests, tensile strength, strain rate, cracking (fracturing), concretes, stress-strain diagrams, cyclic loads, mechanical properties, tensile properties, fracture strength, elastic properties, ductility, strength of materials.

\section{INTRODUCTION}

During the last decade, it was realised that the safety of massive concrete structures such as dams when subjected to earthquakes is often controlled by the tensile behaviour and cracking of the concrete. Therefore, tensile loading tests were carried out and on these results, models describing tensile fracture mechanisms were developed [1, 2]. However, these studies have not examined the tensile strength of concrete at high strain rates after compressive loading. It is generally known that before concrete is loaded, microcracks exist both in the cement matrix and at the interface boundaries between the matrix and aggregate inclusions. These microcracks grow under compressive loading and thus reduce this virgin tensile strength [3-5]. A rheological model to predict the cyclic stress-strain behaviour of concrete subjected to uniaxial compressive loading has also been proposed in [6]

\section{CONCRETE QUALITY CONTROL AND PREPARATION OF SPECIMENS}

The cracking of concrete depends upon the composition of the concrete and the curing conditions. In this work. the curing conditions were kept constant for all these tests thereby reducing the number of parameters affecting mechanical properties

In order to minimize scatter in the test results, particles of both sand and aggregate were graded strictly in accordance with the SIA-162 specification [7] for aggregate sizes between 0 and $32 \mathrm{~mm}$. Sand, aggregate and cement were dry-mixed using a 50 I horizontal mixer for two minutes before mixing with water for a further two minutes. The water-cement ratio was 0.5 and the cement content was $300 \mathrm{~kg} / \mathrm{m}^{3}$

Cylindrical concrete test specimens having a diameter of $150 \mathrm{~mm}$ and a height of $450 \mathrm{~mm}$ were compacted by vibration in plastic moulds. Three days after casting, they were removed from these moulds. Except for the specimens of the first test series (described below), a $5 \mathrm{~mm}$ deep rectangular circumferential notch was sawn at the mid-height of the specimen. The specimens were kept under water during the first two weeks and at $18^{\circ} \mathrm{C}$ and $70 \%$ relative humidity during the second two weeks 
The fresh concrete properties, shown in Table 1, were verified for all test series. The 28-day compressive strength and the elastic modulus are shown in Table 2.

One day before the specimens were tested, both end faces were treated by sand blasting in order to prepare the surface for special steel end caps. The load was to be applied using these tight fitting end caps as shown in Figure 1. The prepared ends of the concrete test cylinders were glued to the end caps using Araldite glue. After one hour of hardening, the test could be performed.

Table 1 Fresh concrete properties (mean value of all test series)

\begin{tabular}{ll}
\hline Workability (Waltz-value) & 1.17 \\
Consistency & plastic \\
Air content $[\mathrm{V}-\%]$ & 1.2 \\
Density $\left[\mathrm{kg} / \mathrm{m}^{3}\right]$ & 2479
\end{tabular}

Table 2 Concrete properties after 28 days

$\begin{array}{ll}\text { Compressive strength }{ }^{*}\left[\mathrm{~N} / \mathrm{mm}^{2}\right] & 37.3(\mathrm{~s}=2.8, \mathrm{n}=13) \\ \text { Modulus of elasticity }\left[\mathrm{kN} / \mathrm{mm}^{2}\right) & 39.80(\mathrm{~s}=2.60, \mathrm{n}=15)\end{array}$

s: standard deviation

$n$ : number of samples

*: using $300 \times 150 \phi$ cylinders

\section{METHOD OF TESTING}

The tests were carried out on a Schenk testing machine (1600 kN) and the deformation was controlled by a constant strain rate. Two different kinds of transducers were used for all the tests. Inductive transducers with a measuring length of $200 \mathrm{~mm}$ were used to control the test by means of the deformation. Three additionat transducers measured the strain over a $100 \mathrm{~mm}$ range using an indirect strain gauge method (Figure 1). The resulting signal was monitored using a digital oscilloscope and the stress-strain relationship was recorded on an $X$-Y plotter

In order to examine the behaviour of concrete in tension after compressive loads, three separate load histories were chosen, as follows:

1) Tensile loading to failure.

2) Compressive loading to various strain levels and subsequent tensile loading to failure.

3) Repeated compressive loading to various strain levels and subsequent tensile loading to failure.

\section{TEST RESULTS}

Failure occurred within the measuring length of the transducer in only twelve $(30 \%)$ of the test specimens Therefore, the stress-strain curves were recorded only to the maximum stress attained, although all tests were strain controlled. The stress-strain relationships of the specimens are shown in Figures 2-5. Figure 6 shows the tensile strength test results of all three load histories in relation to the different strain rates.

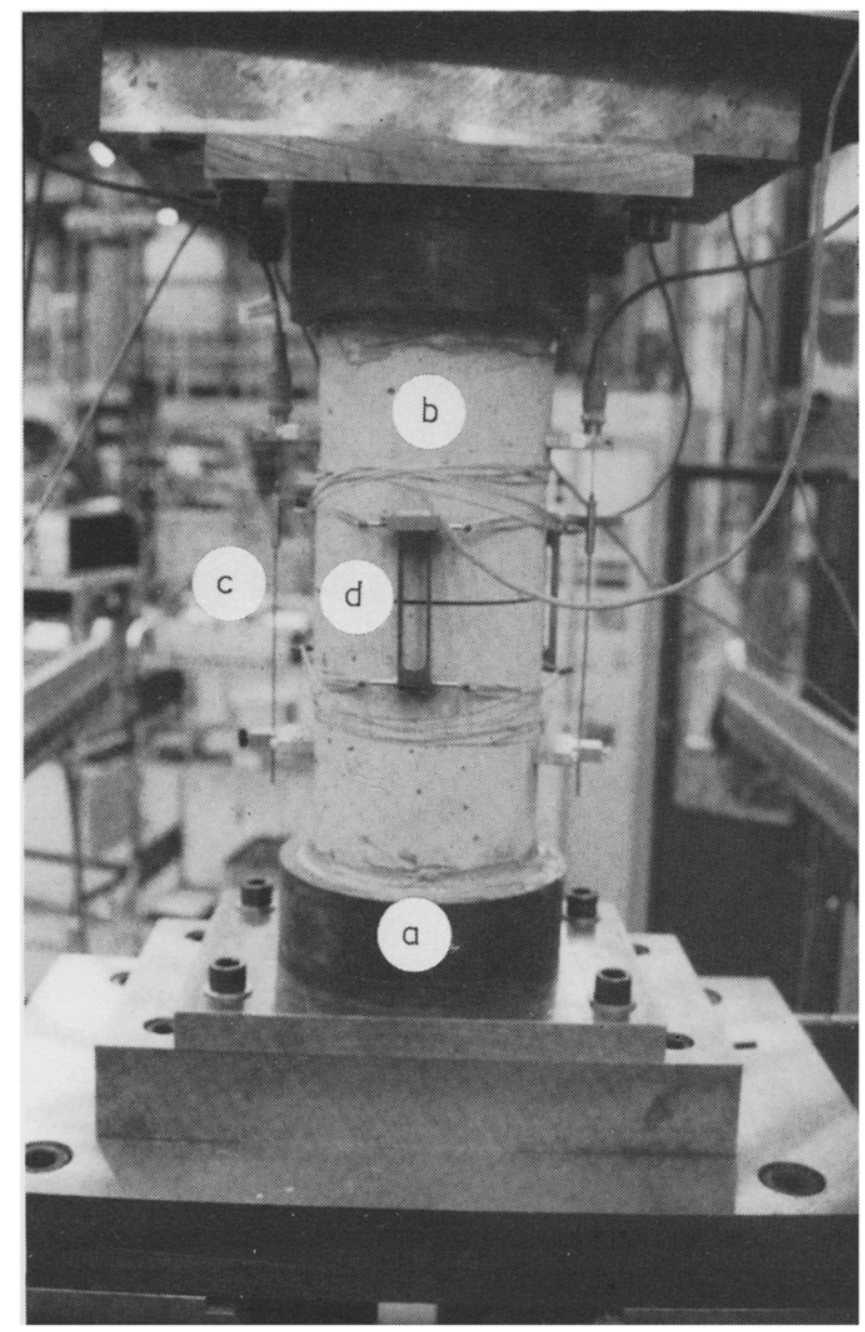

Figure 1 Testing apparatus

a) steet cap

b) specimen

c) inductive transducer (measuring length of 200 $\mathrm{mm}$ )

d) transducer using an indirect strain gauge method (measuring length of $100 \mathrm{~mm}$ )

The results of the three separate loading types with respect to the cracking and fallure characteristics of the specimens are discussed individually below

\section{Tensile loading to failure}

Fifteen unnotched specimens with four different strain rates between $0.01 \cdot 10^{-3} \mathrm{~s}^{-1}$ and $10 \cdot 10^{-3} \mathrm{~s}$ were tested. The following results were obtained:

1) The tensile strength of the concrete and the resulting strains are considerably influenced by the applied strain rates. Both the tensite strength and the failure strain increase with higher strain rates (Figure 2 and 6a)

2) As might be expected, the shape of the stress-strain curve and the measured strain value are dependent 
on whether the failure takes place inside or outside the measuring length of the transducer (Figure 3).

3) The crack surfaces showed that at high strain rates failure occurred through the aggregate inclusions, while this phenomenon was not apparent at low strain rates. The lower the strain rate, the more likely it was that failure took place within the matrix and at its bond with the aggregate.

4) The attained values for the tensile strength are comparable with the results given elsewhere [8].

Compressive loading to various strain levels and subsequent tensile loading to failure

These tests were performed on 29 specimens at four different strain rates. The compressive strains were between $0.25 \cdot 10^{-3}$ and $0.75 \cdot 10^{-3}$. The results are as follows

1) The tensile strength and the resulting strain are influenced by the compressive strain. These values decrease by $10-25 \%$ compared to those of virgin tension loading tests (Figure 4).

2) The two different compressive strain levels do not influence the tensile strength, since the plot of maximum stress versus strain rate does not show any significant scatter (Figure 6b)

3) The tensile strength and the failure strain increase with higher strain rates.

4) The failure characteristics seem to be the same as those of virgin tension loading tests. However, for an increasing magnitude of the applied compressive load, there was a tendency for failure to take place both in the matrix and at the bond between matrix and aggregate but, independently of the applied strain rate

Repeated compressive loading to various strain levels and subsequent tensile loading to failure

The observations of 18 tests are discussed. Firstly 30 constant strain rate cycles were applied. The mean value of the repeated compressive strain were $0.24 \cdot 10^{-3}$ and $0.48 \cdot 10^{-3}$ with amplitudes of $0.12 \cdot 10^{-3}$ and 0.03 . $10^{-3}$. Then tensile loading at three different strain rates to fallure were applied. The results showed the following:

1) The effects of repeated compressive load on the material properties are significant, i.e. the tensile strengths decrease by $40-60 \%$ when compared to the virgin tensile strength (Figure 5).

2) The mean and the amplitude of the repeated strain rate cycles seem to influence the material properties. The higher the mean and the amplitude, the greater is a tendency for a lower tensile strength (Figure 6c).

3) The tensile strength and the failure strain increase with higher strain rates.

4) Generally, the failure occurred in the bond between matrix and aggregate inclusions. The interface boundaries were weakened more severely than the aggregate material due to compressive loading

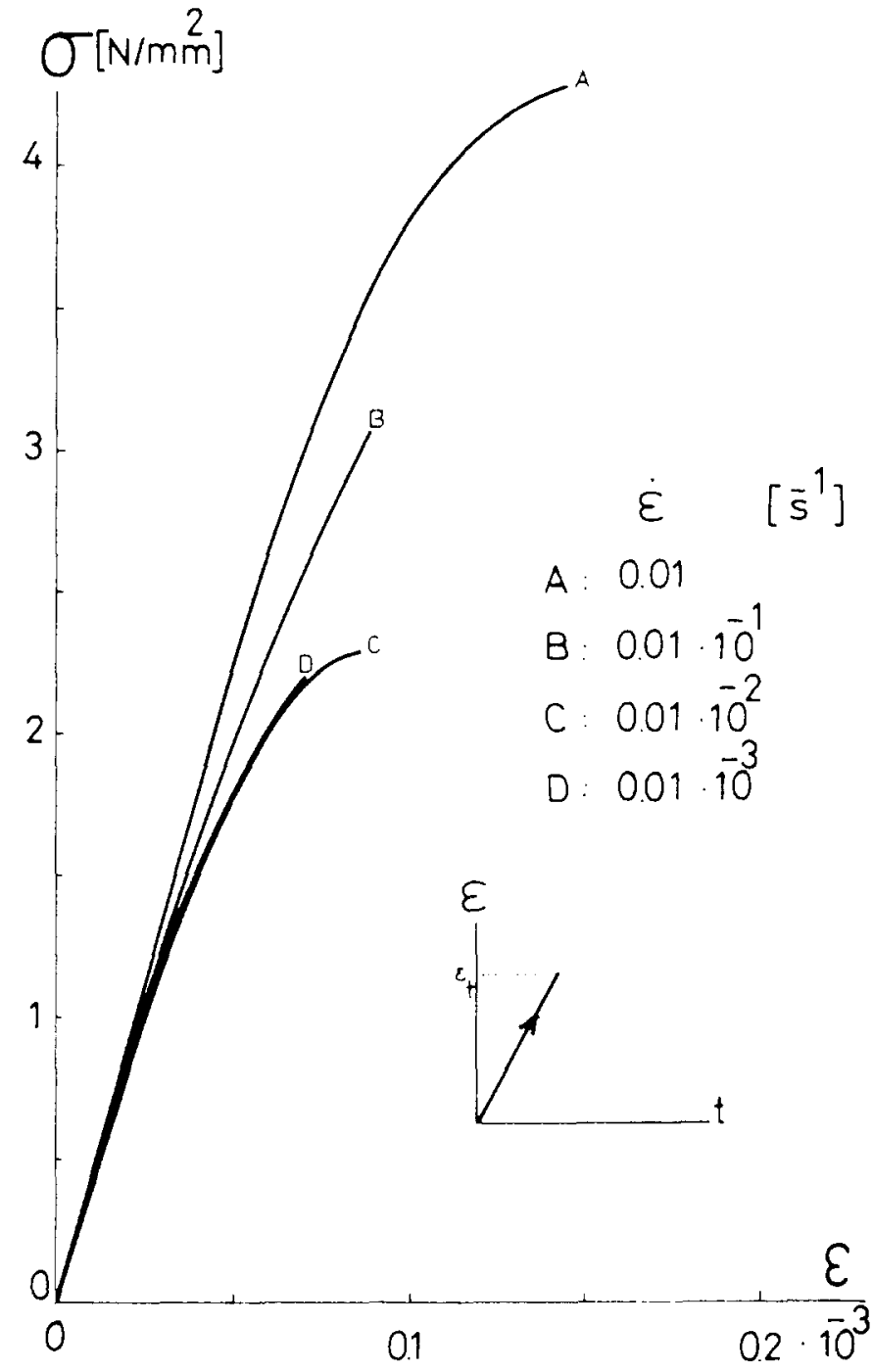

Figure 2 Stress-strain relationships for virgin tensile tests (load history no. 1)

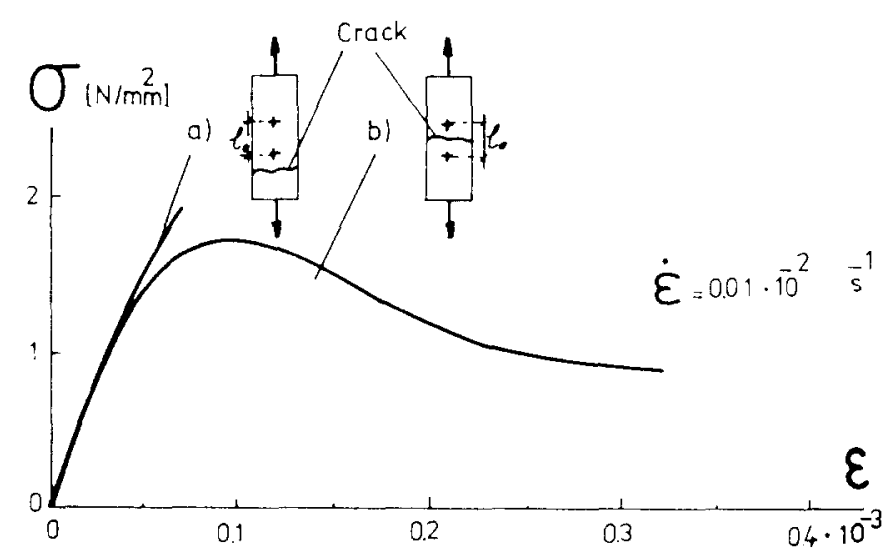

Figure 3 Stress-strain relationships for tensile loading during a deformation controlled test a) failure outside the measuring length $I_{0}$ b) failure inside the measuring length $I_{0}$ 


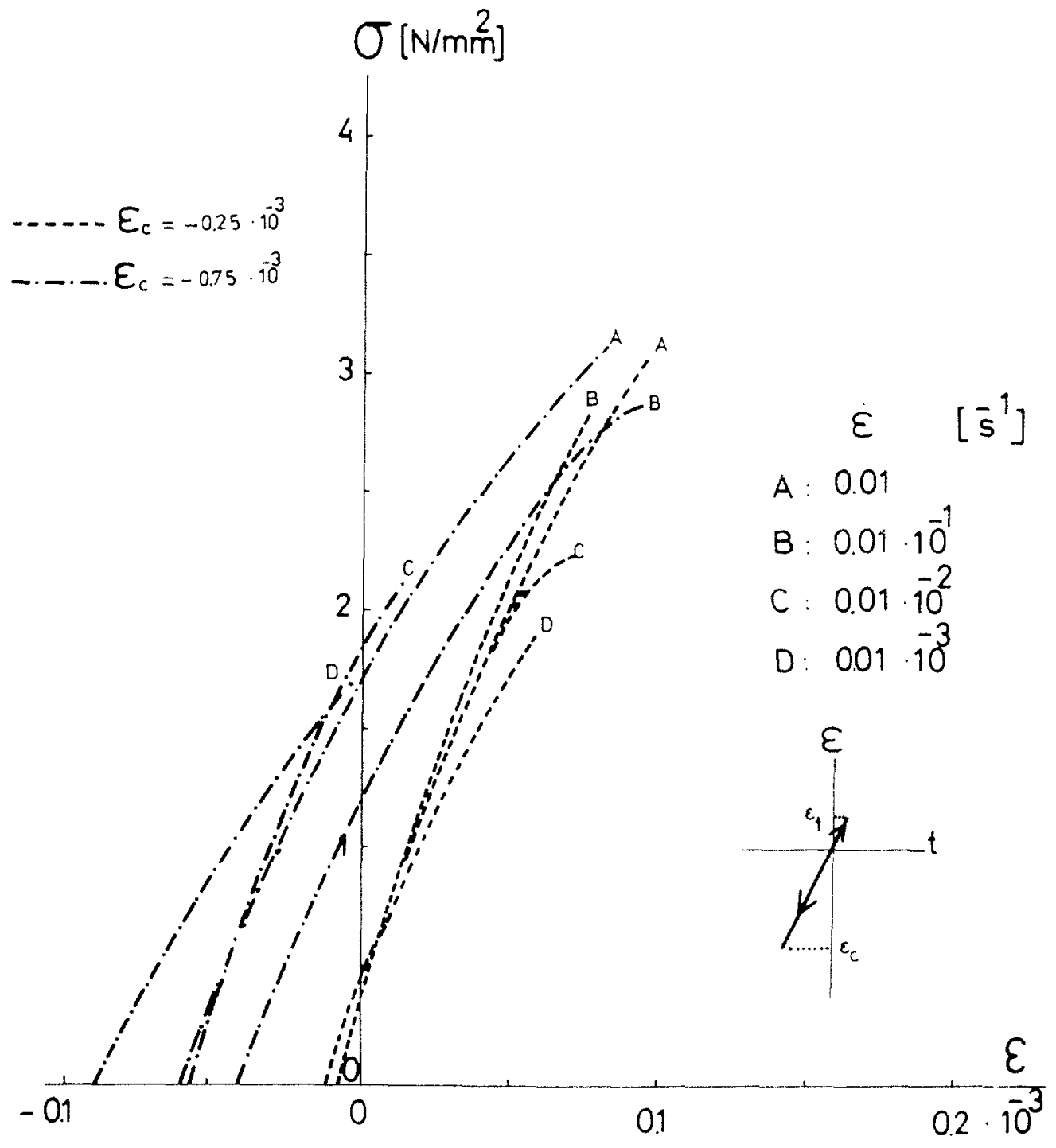

Figure 4

Stress-strain relationships for compressive loading and subsequent tensile loading to failure (load history no. 2)

\section{DESCRIPTION OF FAILURE}

As a consequence of shrinkage effects, microcracks exist in the unloaded concrete mainly at the interface boundaries between the matrix and the aggregates. Upon loading, high stresses occur at the tip of these microcracks. As a result of tensile or compressive strain, these high stresses are relieved by the growth of hair cracks in the matrix and bond cracks at the interface boundaries between the matrix and the aggregates. The material is therefore weakened.

Under increasing tensile strain, the specimen stores energy until total fracture is reached. This fracture energy $\mathrm{G}_{c}$ is described by the area under the entire stress-widening curve (Figure 7a). This curve may be described in two parts. In the first part, which is ascending, the energy gained during loading is not lost upon unloading, i.e. the energy is reversible. However in the second, descending part of the curve, a portion of the energy is lost due to crack-formation and is therefore irreversible. Both reversible and irreversible energy occur at every point of the descending part of the curve. Under increasing strain and decreasing stresses these portions decrease.

Generally, at low strain rates in a deformation controlled tension test, the formation of microcracks is shown by the descending part of the stress-strain diagram once the maximum stress is attained. Furthermore, a successive reduction of reversible energy occurs in this part of the curve. A permanent set remains. The cracks in the matrix are prevented by the aggregates from growing further. Therefore, they are initially stable, i.e. more energy needs to be supplied for their continued propagation. The zone around the microcracks remains capable of carrying load, but in a steadily decreasing amount. This continues untit a critical crack width $w_{c}$ is reached. After this point, the crack is unstable. Finally. the failure occurs at a low reversible energy. The fracture surface grows relatively slowly according to the path of least resistance through the matrix and the interface boundaries around the aggregates, i.e. matrix-failure occurs (Figure 7 b) 


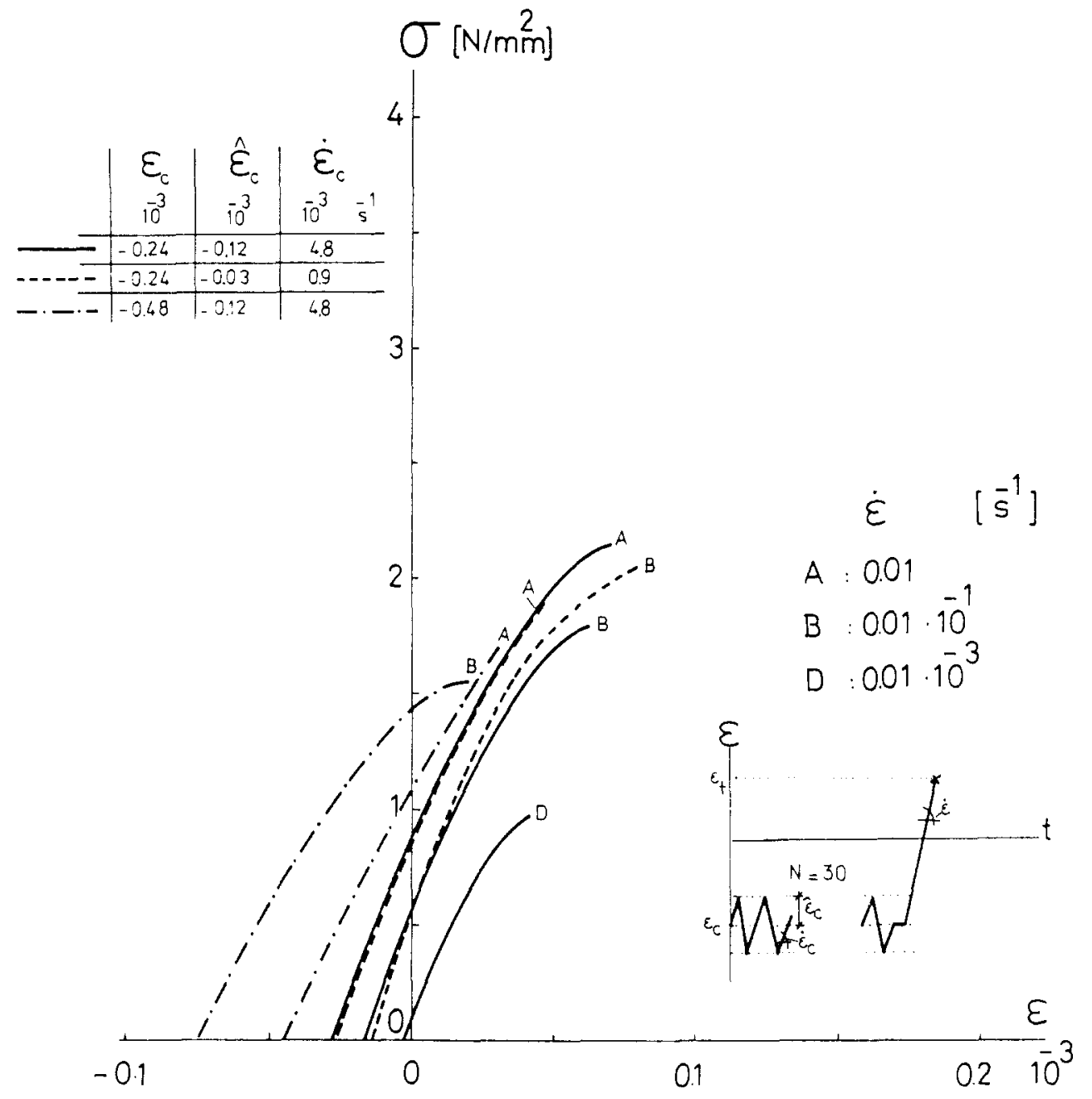

Figure 5

Stress-strain relationships for repeated compressive loading and subsequent tensile loading to failure (load history no. 3)
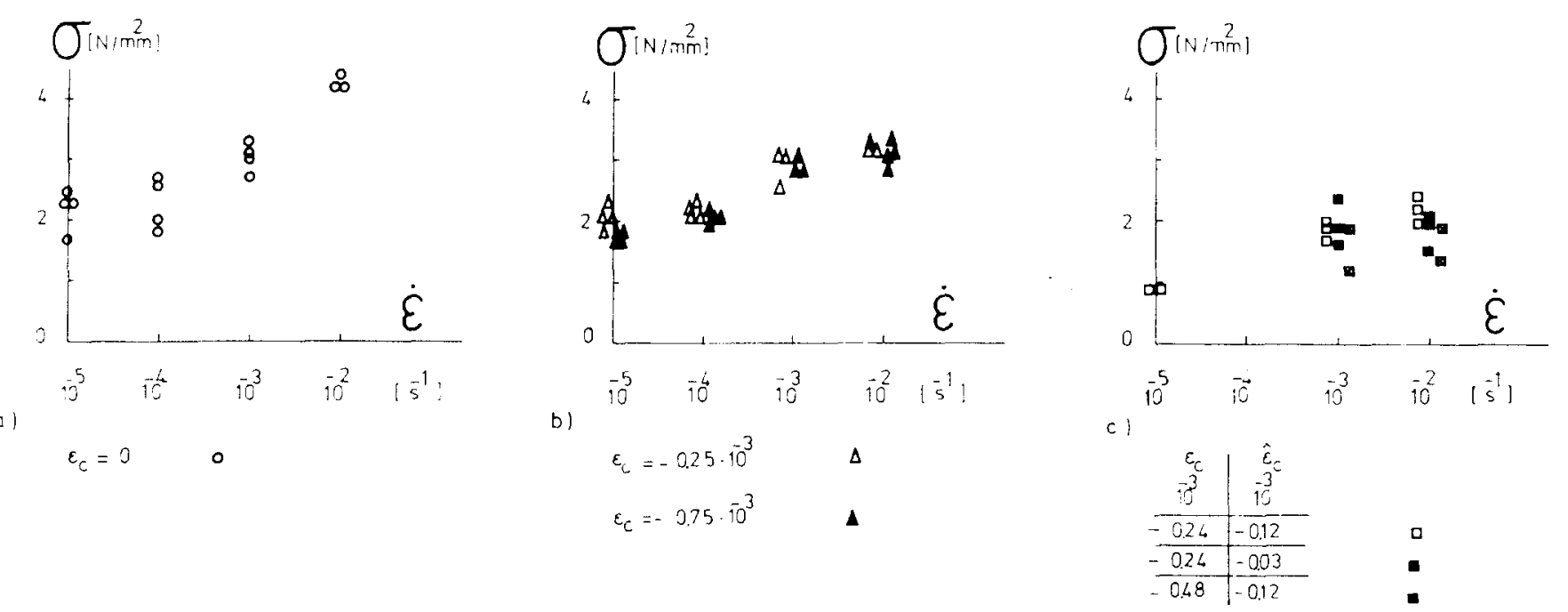

Figure 6 Test results of the tensile strength in relation to the strain rate

a) Virgin tensile tests (load history no. 1)

b) Compressive loading and subsequent tensile loading to failure (load history no. 2)

c) Repeated compressive loading and subsequent tensile loading to failure (load history no. 3) 


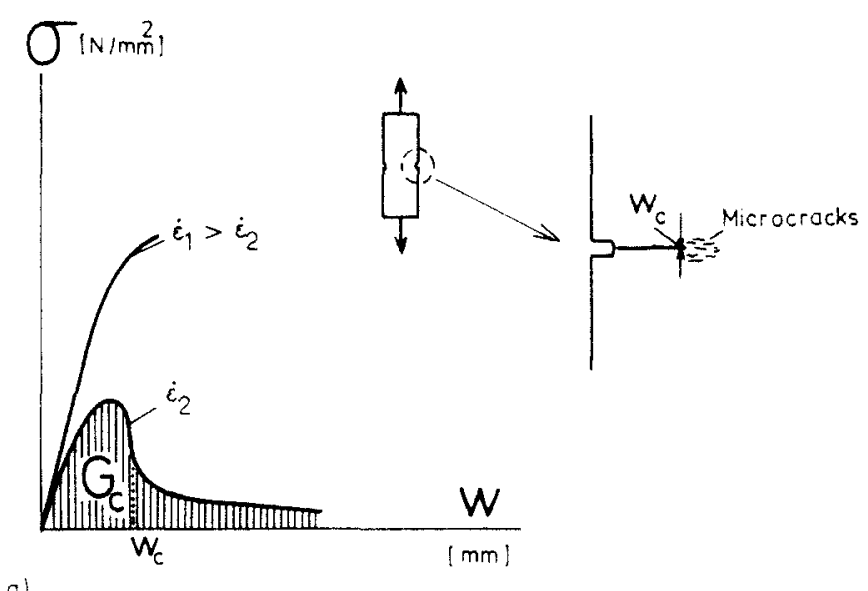

a)
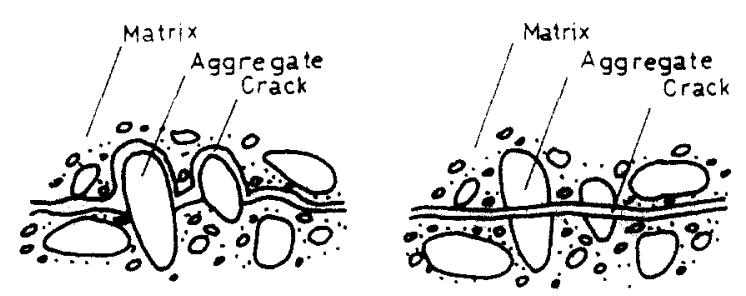

b)

c)

Figure 7 Description of failure (schematic)

a) Failure energy $G_{c}$ and critical value of crack width $w_{c}$

b) Failure characteristics at low strain rates

c) Failure characteristics at high strain rates

Contrary to the behaviour at low tensile strain rates, higher concrete strengths can be observed at high tensile strain rates as a consequence of a delay in the start of the crack propagation. The resulting stored strain energy remains reversible almost until the maximum stress is reached; this is where energy release starts. For a delayed crack propagation the cracks occur spontaneously, i.e. without significant formation of microcracks. As a consequence, there is a greater amount of energy released, the cracks are no longer stable and they propagate unhindered and relatively quickly. The failure then occurs according to a relatively direct path through the matrix and the aggregates themselves (Figure $7 \mathrm{c}$ ).

\section{CONCLUSIONS}

The test results can be summarized by the following points:

1. Significant differences were obtained for the tensile strength at various compressive load histories. The tensile strength is sensitive to initial compressive load.
2. The influence of the strain rate on the tensile strength in the deformation controlled tests is apparent, i.e. the tensile strength may increase due to high strain rates.

3. Under the influence of an initial compressive strain history, the crack is propagated through the matrix and the bond between matrix and aggregate. The interface boundaries are weakened due to compressive loading

\section{ACKNOWLEDGEMENTS}

This research was performed under the auspices of DrR. Biedermann, head of the Swiss Federal Direction of the Water Economy. (Bundesamt für Wasserwirtschaft, Bern) and Prof. Dr A. Rösli at the Swiss Federal Institute of Building Materials (IBWK, ETH Zürich). The writers appreciate their support in the publishing of this paper. In addition, thanks are due to M. J. Fidler and Dr F. C. Smith for their work in assisting with the translation

\section{REFERENCES}

1. Zielinski. A. J. 'Model for tensile fracture of concrete at high strain rates of loading', Cement and Concrete Research, Vol. 14, No. 2, March 1984, pp. 215-24

2. Reinhardt, H.W. 'Fracture mechanics of an elastic softening material like concrete', Heron, Vol. 29 No. 2, 1984, 42p

3. Morita, S., Kaku, T. and Sudo, E. 'Force-strain relationship of reinforcing bars embedded in concrete under reversed loadings', Comité Euro International du Béton, (Rome) Bulletin D'Information. No. 132, 1979, pp. 7-14

4. Tiniç, $C$. 'Versuche über das Verformungsverhalten von Beton unter Zug-bzw. Druck-Zugbeanspruchung bei verschiedenen Dehngeschwindigkeiten', IBWK-Bericht, ETH Zürich, April 1983, 24p.

5. Brühwiler, E. 'Beschreibung des Zugverhaltens von Beton bei rascher Beanspruchung und nach Vorbelastung', Diplomarbeit, IBWK, ETH Zürich. December 1983, pp. 6-28.

6. Fafitis, A and Shah, S. P. 'Rheological model for cyclic loading of concrete', Journal of Structural Engineering. Proceedings, American Society of Civil Engineers, Vol. 110. No. 9. September 1984. pp. 2085-2102.

7. SIA-Norm 162: 'Norm fur die Berechnung, Konstruktion und Ausführung von Bauwerken aus Beton, Stahlbeton und Spannbeton', Schweizerischer Ingenieur und. Architekten-Verein SIA, Zürich, 1968, pp. 3-5.

8. Suaris, W. and Shah, S. P. Mechanical properties of materials subjected to impact'. RILEM Symposium. Concrete Structures Under Impact and Impulsive Loading, Berlin, June 1982, Introductory Report, pp. $33-62$ 